\title{
Prevalence and distribution of various human papillomavirus genotypes in women with high risk for cervical carcinoma
}

\author{
Sheenu Maheshwari ${ }^{1}$, Ruchira Nautiyal ${ }^{1 *}$, Aarti Kotwal ${ }^{2}$, Smita Chandra $^{3}$
}

\begin{abstract}
${ }^{1}$ Department of Obstetrics and Gynecology, ${ }^{2}$ Department of Microbiology, ${ }^{3}$ Department of Pathology, Himalayan Institute of Medical Sciences, Dehradun, Uttarakhand, India
\end{abstract}

Received: 23 March 2020

Accepted: 22 April 2020

\section{*Correspondence:}

Dr. Ruchira Nautiyal,

E-mail: ruchiranautiyal@srhu.edu.in

Copyright: $\odot$ the author(s), publisher and licensee Medip Academy. This is an open-access article distributed under the terms of the Creative Commons Attribution Non-Commercial License, which permits unrestricted non-commercial use, distribution, and reproduction in any medium, provided the original work is properly cited.

\section{ABSTRACT}

Background: In India, cervical cancer is second most common cancer in women and is the second most common cause of death due to cancers in women. Human papillomavirus (HPV), mainly genotype 16 and 18, are responsible for most of the precancerous lesions of cervix and for cervical cancer. Therefore, it is necessary to prevent the spread of HPV infection and its early treatment to decrease cervical cancer associated morbidity and mortality. Aims of this study was to find out the prevalence and distribution of various HPV genotypes in women high risk for cervical carcinoma. To find correlation between HPV DNA test and cytology report.

Methods: An observational study was done on a total of 384 women who were at a high risk for cervical cancer. Ectocervix and endocervix samples for conventional cytology along with cervical swab collection for HPV DNA isolation were obtained from women aged 21-65 years. Multiplex real time PCR used for HPV DNA isolation and genotyping and Bethseda classification 2014 was used for reporting cytology. Statistical analysis was done using SPSS version 22 and Microsoft excel 2010 software. Data assessment was done using independent t-test, Chi-square test or Fisher's exact test.

Results: Prevalence of HPV in women high risk for cervical cancer in our study was $14.58 \%$. Most common highrisk genotypes were HPV 18 (7.03\%) followed by HPV 16 (6.51\%). All genotypes except genotype 31, were more frequently seen as a single infection rather than a multiple infection. In 323 subjects which were negative for Pap smear, 31 were positive for HPV DNA showing a statistically significant result with a p value of $<0.0001$.

Conclusions: It was analysed that infection with HPV is very common (9.60\%) even in women who had a negative Pap smear test showing a positive correlation between the two tests. HPV DNA testing can improve the detection rate of cervical intraepithelial lesions.

Keywords: Cervical cancer, Genotype, Human papillomavirus, Human papillomavirus deoxyribonucleic acid, Pap smear

\section{INTRODUCTION}

Cervical cancer is the third most common cancer in world and second most common cancer in females in India. ${ }^{1}$ It is the second common cause of death due to cancer in women in India with about 60,078 deaths occurring annually. ${ }^{1}$ Human papilloma virus (HPV) is the most common infection that is acquired sexually in the world with a prevalence of about $50 \%$ in young adolescents that are sexually active. ${ }^{2}$ There is a wide variation in the HPV prevalence and its genotypic distribution and this is due to different socio-economic and geo-climatic condition. ${ }^{3}$ High prevalence is related to presence of risk factors such as early age of first intercourse, polygamous relationship, presence of STI's including HIV. ${ }^{4}$ Furthermore, the incidence rate continues to rise at a rapid pace each year, underscoring the need for preventative measures and access to treatment. Infection with high risk oncogenic genotypes of the HPV has been established as a necessary cause of cervical cancer. Genotype 16 and 18 are 
responsible for about $2 / 3^{\text {rd }}$ of cervical carcinoma in world. Therefore, it is crucial that prevention of the spread of HPV to be considered a major priority where most cervical cancer deaths occur.

\section{METHODS}

This study was conducted in the department of obstetrics and gynecology in coordination with department of microbiology and department of pathology at Himalayan Institute of Medical Sciences, Dehradun over a period of 12 months (from October 2017-October 2018). Total 384 women who are at high risk for cervical carcinoma between 21-65 years of age visiting gynecology outpatient department was included in the study after obtaining written informed consent and ethical clearance from the institutional ethics committee.

\section{Inclusion criteria}

- Women at high risk for cervical cancer between 2165 years of age

- Early age of marriage

- Early age of sexual activity

- Multiparous women

- Long term oral contraceptive pill users

- Women with signs and symptoms of STI

- Women with HIV

- $\quad$ Pregnant women with profuse vaginal discharge and bad cervix

- Unsatisfactory cytology report.

\section{Exclusion criteria}

- Unmarried females

- Women not sexually active

- Women who had total hysterectomy

- Women with age $<21$ years and $>65$ years.

\section{Study protocol}

The complete history (name, age, sex, occupation, residential address, chief complaints and history of presenting illness, obstetrical history, menstrual history, past history, personal history, behavioural history, family history and drug history) was taken.

- A clinical examination of vulva, vagina and cervix was done for evidence of any warts, ulcers, discharge or any lesion

- Ayer's spatula and cytobrush was used to take ectocervix and endocervix samples for conventional cytology using Pap smear along with cervical swab collection for HPV DNA isolation

- Bethseda classification 2014 was used for reporting cytology

- Multiplex real time PCR used for HPV DNA isolation and genotyping.

\section{Statistical analysis}

Data assessment was done using SPSS version 22 and Microsoft excel 2010 software. Categorical variables were presented in number and percentage (\%) and continuous variables were presented as mean \pm SD. Normality of data was tested by Kolmogorov-Smirnov test. If the normality was rejected then non parametric test was used. Quantitative variables were compared using Independent t-test between the two groups (HPV DNA positive and HPV DNA negative women). Qualitative variables were correlated using Chi-square test/ Fisher's Exact test. Univariate and multivariate logistic regression was used to find out significant factors affecting HPV DNA positivity and Pap smear positivity.

\section{RESULTS}

Total three hundred eighty-four cases were taken.

Table 1: Socio-demographic characteristics of the study population $(n=384)$.

\begin{tabular}{|c|c|c|}
\hline \multicolumn{2}{|c|}{ Demographics } & n $(\%)$ \\
\hline \multirow{6}{*}{$\begin{array}{l}\text { Age in } \\
\text { years }\end{array}$} & Mean \pm SD (range) & $39.96 \pm 7.74$ \\
\hline & $21-30$ & $32(8.33 \%)$ \\
\hline & $31-40$ & $201(52.34 \%)$ \\
\hline & $41-50$ & $114(26.69 \%)$ \\
\hline & $51-60$ & $34(8.85 \%)$ \\
\hline & $61-65$ & $3(0.78 \%)$ \\
\hline \multirow{4}{*}{ Education } & Never been to school & $27(7.03 \%)$ \\
\hline & Primary & $64(16.67 \%)$ \\
\hline & Secondary & $128(33.33 \%)$ \\
\hline & Tertiary & $165(42.97 \%)$ \\
\hline \multirow{3}{*}{ Occupation } & Housewife & $252(65.63 \%)$ \\
\hline & Employed & $97(25.26 \%)$ \\
\hline & Self-employed & $35(9.11 \%)$ \\
\hline \multirow{4}{*}{ Parity } & 0 & $7(1.82 \%)$ \\
\hline & 1 & $30(7.81 \%)$ \\
\hline & 2 & $173(45.05 \%)$ \\
\hline & $3+$ & $174(45.31 \%)$ \\
\hline \multicolumn{2}{|c|}{ Age at first intercourse: Mean \pm SD } & $21.17 \pm 2.27$ \\
\hline \multicolumn{2}{|c|}{ Age at menopause: Mean age \pm SD } & $47.86 \pm 2.45$ \\
\hline \multirow{3}{*}{$\begin{array}{l}\text { Number of } \\
\text { sexual life } \\
\text { partner }\end{array}$} & 1 & $100(100 \%)$ \\
\hline & 2 & $0(0.0 \%)$ \\
\hline & $3+$ & $0(0.0 \%)$ \\
\hline \multirow{2}{*}{$\begin{array}{l}\text { Ever had } \\
\text { STI }\end{array}$} & Yes & $5(1.3 \%)$ \\
\hline & No & $379(98.70 \%)$ \\
\hline \multirow{2}{*}{ HIV status } & Positive & $1(0.26 \%)$ \\
\hline & Negative & $383(99.745 \%)$ \\
\hline \multirow{2}{*}{ Smoking } & Yes & $6(1.56 \%)$ \\
\hline & No & $378(98.44 \%)$ \\
\hline \multirow{2}{*}{ Alcohol } & Yes & $3(0.78 \%)$ \\
\hline & No & $381(99.22 \%)$ \\
\hline
\end{tabular}

All 384 patients were subjected to cervical Pap smear preparation by conventional Pap smear method and real 
time PCR is used for HPV DNA testing and results of both tests were compared.

Out of 384 women, 56 were positive for HPV DNA testing. Therefore, the prevalence of HPV in women high risk for cervical cancer in our study was $14.58 \%$.

Table 1 shows that out of 384 women, minimum age seen was 21 years and maximum age was 65 years with a mean age of about 39 years. Maximum number of women, $201(52.34 \%)$ were in the reproductive age group of 31-40 years and least number were seen in the age group of more than 60 years accounting to $3(0.78 \%)$. Most of the women (57\%) were educated only upto high school in our study.
Table 2 shows that overall prevalence of HPV infection in our study population was $14.58 \%$ with the peak age prevalence of $18.41 \%$ in $31-40$ years of age with a $p$ value of 0.03 that is statistically significant. Persistent HPV infection (19.35\%) was seen in women with age $>40$ years. Thirty four percent of women with infection with HPV had a parity of 2 and more (p value of 0.012 ). Among women with HPV positive, $54.56 \%$ women had education upto high school. Smoking and alcohol consumption were significantly associated with HPV infection with a $\mathrm{p}$ value of 0.043 and 0.003 respectively.

Age at first coitus, any past history of STIs, age at menopause and HPV infection were found to be statistically insignificant.

Table 2: Association of HPV infection with various socio-demographic factors $(n=384)$.

\begin{tabular}{|c|c|c|c|c|c|c|}
\hline & \multicolumn{2}{|l|}{ HPV DNA test } & \multirow{2}{*}{ Total } & \multirow{2}{*}{\multicolumn{2}{|c|}{ p value }} \\
\hline & & Negative & Positive & & & \\
\hline \multirow{6}{*}{$\begin{array}{l}\text { Age distribution } \\
\text { (years) }\end{array}$} & $21-30$ & $28(87.50 \%)$ & $4(12.50 \%)$ & 32 & \multirow{5}{*}{0.249} & 1.000 \\
\hline & $31-40$ & $164(81.59 \%)$ & $37(18.41 \%)$ & 201 & & 0.030 \\
\hline & $41-50$ & $102(89.47 \%)$ & $12(10.53 \%)$ & 114 & & 0.157 \\
\hline & $51-60$ & $31(91.18 \%)$ & $3(8.82 \%)$ & 34 & & 0.447 \\
\hline & $>60$ & $3(100.00 \%)$ & $0(0.00 \%)$ & 3 & & 1.000 \\
\hline & Total & $328(85.42 \%)$ & $56(14.58 \%)$ & 384 & & \\
\hline \multirow{4}{*}{ Education } & Never been to school & $22(81.48 \%)$ & $5(18.52 \%)$ & 27 & \multirow{4}{*}{0.132} & 0.570 \\
\hline & Primary & $49(76.56 \%)$ & $15(23.44 \%)$ & 64 & & 0.034 \\
\hline & Secondary & $112(87.50 \%)$ & $16(12.50 \%)$ & 128 & & 0.447 \\
\hline & Tertiary & $145(87.88 \%)$ & $20(12.12 \%)$ & 165 & & 0.247 \\
\hline \multirow{3}{*}{ Occupation } & Employed & $85(87.63 \%)$ & $12(12.37 \%)$ & 97 & \multirow{3}{*}{0.607} & 0.618 \\
\hline & Housewife & $212(84.13 \%)$ & $40(15.87 \%)$ & 252 & & 0.363 \\
\hline & Self-employed & $31(88.57 \%)$ & $4(11.43 \%)$ & 35 & & 0.802 \\
\hline \multirow{2}{*}{ Smoking } & No & $325(85.98 \%)$ & $53(14.02 \%)$ & 378 & \multirow{2}{*}{\multicolumn{2}{|c|}{0.043}} \\
\hline & Yes & $3(50.00 \%)$ & $3(50.00 \%)$ & 6 & & \\
\hline \multirow{2}{*}{ Alcohol } & No & $328(86.09 \%)$ & $53(13.91 \%)$ & 381 & \multirow{2}{*}{\multicolumn{2}{|c|}{0.003}} \\
\hline & Yes & $0(0.00 \%)$ & $3(100.00 \%)$ & 3 & & \\
\hline \multirow{2}{*}{ History of any STI } & No & $325(85.75 \%)$ & $54(14.25 \%)$ & 379 & \multirow{2}{*}{0.156} & \\
\hline & Yes & $3(60.00 \%)$ & $2(40.00 \%)$ & 5 & & \\
\hline \multirow{3}{*}{ Parity } & 1 & $29(96.67 \%)$ & $1(3.33 \%)$ & 30 & \multirow{3}{*}{0.012} & \\
\hline & 2 & $136(78.61 \%)$ & $37(21.39 \%)$ & 173 & & \\
\hline & $3+$ & $158(87.29 \%)$ & $23(12.71 \%)$ & 181 & & \\
\hline Age at first intercourse & Mean \pm SD & $21.22 \pm 2.3$ & $20.89 \pm 2.09$ & 0.401 & & \\
\hline Age of menopause & Mean \pm SD & $47.9 \pm 2.54$ & $47.57 \pm 1.81$ & 0.531 & & \\
\hline
\end{tabular}

Fisher's Exact test, Chi square test, Independent $t$ test.

Table 3 shows that among HPV positive women, post coital bleeding was seen in $28.89 \%$ followed by intermenstrual bleeding in $28.57 \%$ which shows a statistically significant results with a p value of 0.011 and 0.029 respectively. Vulval itching, abnormal vaginal discharge and menorrhagia contributes to about $19.72 \%, 16.77 \%$ and $13.48 \%$ respectively in women positive for HPV DNA. Figure 1 shows that out of 384 women, 61 (15.89\%) had abnormal cytology. Most common being LSIL contributing to about $11.2 \%$ followed by ASCUS
$(1.82 \%)$ and AGC (1.04\%). With almost similar percentage of HSIL (0.78\%), AGUS and ASC-H $(0.52 \%$ each). Figure 2 depicts that out of total HPV positive cases, the largest proportion $(85.71 \%)$ of the tested population were positive for only a single high-risk HPV type while the remaining samples have multiple combinations of HPV types with genotypes 16,18 and 16,31 being the commonest $(5.36 \%$ each). Other combinations seen were genotypes $16,31,33,35$ and 31 , $33,35,39$. 
Table 3: Relationship between symptoms at the time of presentation and HPV infection.

\begin{tabular}{|llll|}
\hline & HPV DNA test & Positive & p value \\
\cline { 2 - 4 } & Negative & $13(28.89 \%)$ & 0.011 \\
\hline Post coital bleeding & $32(71.11 \%)$ & $8(28.57 \%)$ & 0.029 \\
\hline Inter-menstrual bleeding & $20(71.43 \%)$ & $27(16.77 \%)$ & 0.302 \\
\hline Abnormal vaginal discharge & $134(83.23 \%)$ & $14(19.72 \%)$ & 0.175 \\
\hline Vulval itching or burning & $57(80.28 \%)$ & $5(15.63 \%)$ & 0.862 \\
\hline Pain during intercourse & $27(84.38 \%)$ & $6(13.64 \%)$ & 0.850 \\
\hline Post-menopausal bleeding & $38(86.36 \%)$ & $19(13.48 \%)$ & 0.639 \\
\hline Menorrhagia & $122(86.52 \%)$ & $3(5.56 \%)$ & 0.058 \\
\hline Persistent dysuria & $51(94.44 \%)$ & $2(40.00 \%)$ & 0.156 \\
\hline Loss of appetite & $3(60.00 \%)$ & $2(25.00 \%)$ & 0.330 \\
\hline Myalgia & $6(75.00 \%)$ & & \\
\hline
\end{tabular}

Fisher's Exact test, Chi square test.

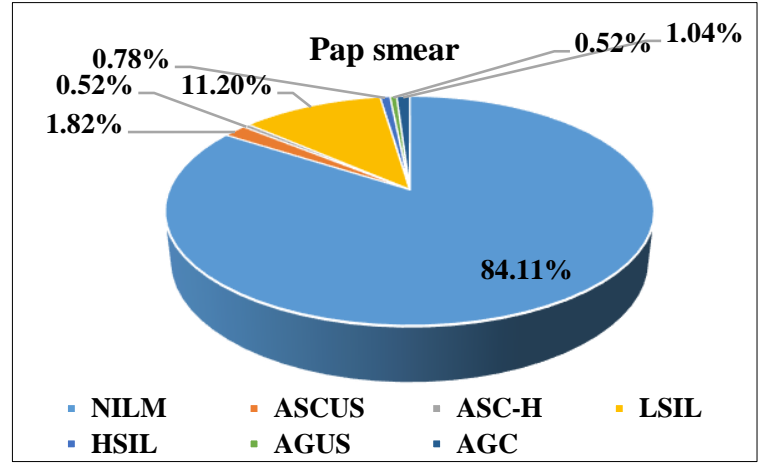

Figure 1: Results of cytology tests in women high risk for cervical carcinoma.

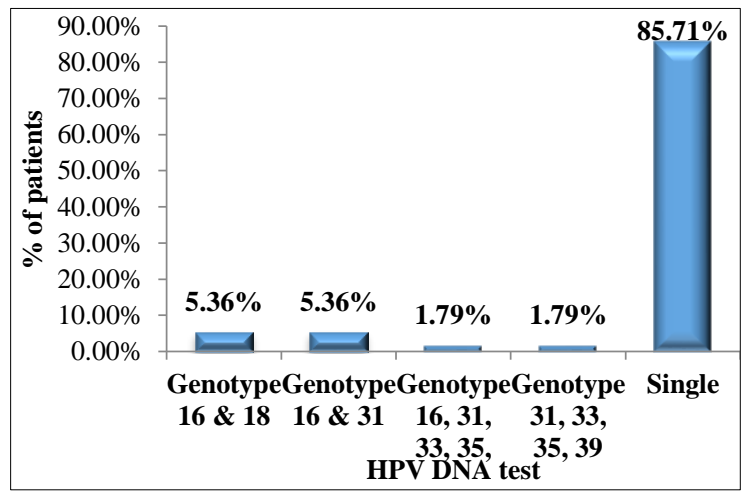

Figure 2: Combination of HPV genotypes in study population.

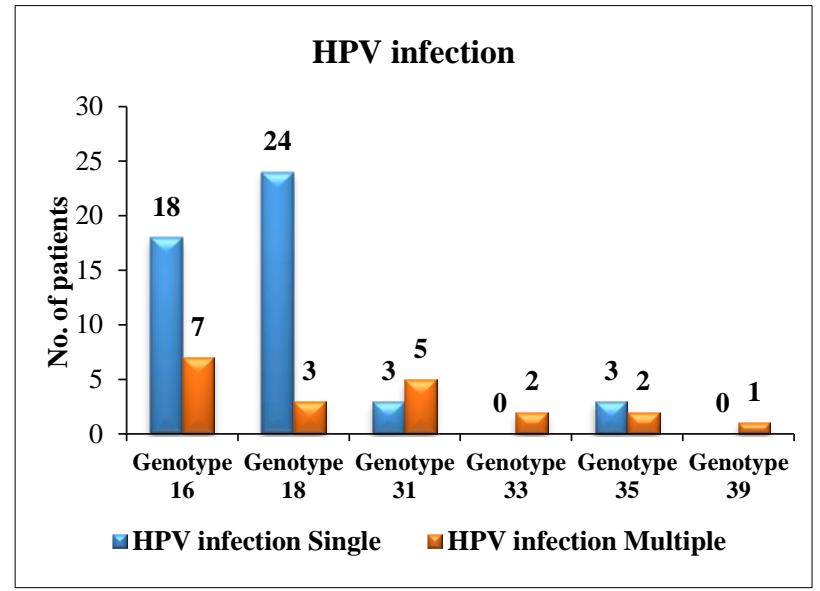

Figure 3: Distribution of HPV genotypes in the study population.

Figure 3 shows that the most common high-risk genotypes of HPV was HPV 18, which was present in 27 subjects $(7.03 \%)$ followed by HPV 16 (6.51\%). Other high-risk genotypes found were HPV 31 (2.08\%), 35 $(1.30 \%), 33(0.52 \%)$ with genotype 39 being least common. All genotypes except genotype 31, were more frequently seen as a single infection rather than a multiple infection. Table 4 depicts that 31 subjects were positive for HPV DNA in 323 subjects which were negative for Pap smear showing a statistically significant result with a $\mathrm{p}$ value of $<0.0001$.

Table 4: Correlation between HPV testing and cytology.

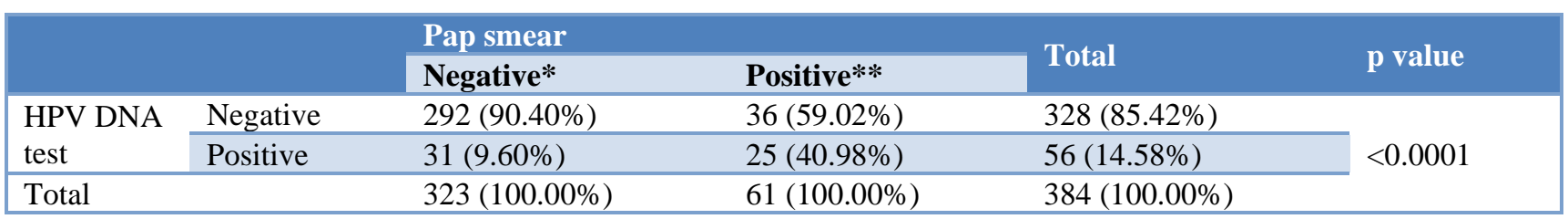

Chi square test *Negative Pap smear is equivalent to NILM cytology, **Positive Cytology is equivalent with ASCUS+. 


\section{DISCUSSION}

It was seen that maximum number of subjects positive for HPV DNA were in between 31-40 years of age (18.41\%). Despite of the fact that most of the infections due to HPV resolved spontaneously in the reproductive age group, we observed a persistence of HPV infection in subjects with age more than 40 years $(19.35 \%)$. Kennedy et al observed a persistence of HPV infection in females more than 40 years of age $(25 \%)$ with highest number of HPV positive cases $(62 \%)$ in reproductive age group. ${ }^{5}$ Similar results were reported by Usha et al in Guwahati with increased prevalence of infection with HPV $(21.4 \%)$ in females more than 50 years of age due to persistent infection. ${ }^{6}$ Study results were in concordance with the results reported by Mayrand et al and from Eastern India by Dutta $\mathrm{S}$ et al. ${ }^{7,8}$

It was also observed that parity of 2 or more is an important risk factor. This may be due to early age of marriages in semi-urban India resulting in early child bearing. Kennedy et al found that infection with HPV was higher in females with parity of 3 or more. ${ }^{5}$ The risk of smoking and alcohol in women was also assessed and were found to be statistically significant but these findings were not in consistent with findings in the above-mentioned studies. It was also observed in this study that low education level was one of the risk factors for developing HPV infection. Thus, lack of education has been associated with the high-risk sexual practices and a poor health seeking attitude, cumulating in the increased presence of sexually transmissible infections like HPV. ${ }^{9}$

The prevalence of HPV (14.58\%) in our study was in the lower distribution of the global estimates. A comparable prevalence of HPV in India was reported by Clifford et al (14\%) which was slightly higher than other Asian countries like in Vietnam $(9.2 \%)$, Thailand $(6 \%)$ and Korea $(8.5 \%) .^{10}$

The most prevalent HPV genotypes reported in our study was HPV 18 whereas HPV 16 is the most prevalent genotype reported worldwide. ${ }^{11}$ The prevalence of other genotypes varies according to ethnicity and geography. ${ }^{11}$ In a study conducted in southern India, it was seen that in general population the most prevalent genotype found was HPV 16 which affects $22.5 \%$ of HPV positive women. ${ }^{12}$

In this study, there was a positive correlation between the two screening methods (Pap smear and HPV DNA testing). Three twenty-three women out of 384 had a normal cytology. Among these, 31(9.60\%) were positive for HPV DNA. LSIL (11.20\%) was the most common cytological abnormality seen in women positive for HPV in this study and was more frequently associated with HPV genotype $18(45.83 \%)$ as compared to $16(27.78 \%)$. HSIL was more commonly associated with genotype 16
(16.67\%). In Guwahati, India, Usha et al reported that HSIL were more frequently seen lesions in women who were infected with HPV genotype 16 and 18 as compared to women with LSIL. ${ }^{6}$

Limitations of this study is that population we included is relatively small and is limited to the patient visiting our outpatient gynecology department. Therefore, conclusion from the present study could not be generalized further. Also, specificity and sensitivity of HPV test and Pap testing is not determined as no gold standard test was used.

\section{CONCLUSION}

A significant result was found between the two tests (HPV DNA and cytology) in this study. Thus, early detection of pre-cancerous lesion by HPV DNA testing and triage may reduce the morbidity and mortality due to cervical carcinoma. Therefore, if a reasonable subsidized cost of HPV DNA technique is available, then it will be cost effective and feasible to include it in the armamentarium of cervical screening as co-testing.

Funding: No funding sources Conflict of interest: None declared

Ethical approval: The study was approved by the Institutional Ethics Committee

\section{REFERENCES}

1. Bruni L, Albero G, Serrano B, Mena M, Gómez D, Muñoz J, Bosch FX, de Sanjosé S. ICO/IARC Information Centre on HPV and Cancer (HPV Information Centre). Human papillomavirus and related diseases in India. Summary Report 10 December 2018.

2. Hernandez BY, Wilkens LR, Zhu X, Thompson P, McDuffie K, Shvetsov YB, et al. Transmission of human papillomavirus in heterosexual couples. Emerging Infect Dis. 2008;14(6):888-96.

3. Srivastava S, Shahi UP, Dibya A, Gupta S, Roy JK. Distribution of HPV genotypes and involvement of risk factors in cervical lesions and invasive cervical cancer: a study in an Indian population. Int $\mathbf{J}$ Mol Cellular Med. 2014;3(2):61-9.

4. Ginindza TG, Dlamini X, Almonte M, Herrero R, Jolly PE, Tsoka-Gwegweni JM, et al. Prevalence of and associated risk factors for high risk human papillomavirus among sexually active women, Swaziland. PloS one. 2017;12(1):e0170-89.

5. Kennedy NT, Ikechukwu D, Goddy B. Risk factors and distribution of oncogenic strains of human papillomavirus in women presenting for cervical cancer screening in Port Harcourt, Nigeria. Pan African Med J. 2016;23(1):21-32.

6. Sarma U, Mahanta J, Borkakoty BJ, Talukdar KL, Gogoi R, Yadav K. Demographic characteristic of HPV infection in women-a hospital-based study 
from Guwahati, India. National $\mathrm{J}$ Med Res. 2013;3(1):1-4.

7. Mayrand MH, Duarte-Franco E, Rodrigues I, Walter SD, Hanley J, Ferenczy A, et al. Human papillomavirus DNA versus Papanicolaou screening tests for cervical cancer. $N$ Eng $J$ Med. 2007;357(16):1579-88.

8. Dutta S, Begum R, Mazumder D, Mandal SS, Mondal R, Biswas J, Dey B, et al. Prevalence of human papillomavirus in women without cervical cancer: a population-based study in Eastern India. Int J Gynecol Pathol. 2012;31(2):178-83.

9. Esere MO. Effect of sex education programme on atrisk sexual behaviour of school-going adolescents in Ilorin, Nigeria. African Health Sci. 2008;8(2):120-5.

10. Clifford GM, Gallus S, Herrero R, Muñoz N, Snijders PJ, Vaccarella $S$, et al. IARC HPV Prevalence Surveys Study Group: Worldwide distribution of human papillomavirus types in cytologically normal women in the International
Agency for Research on Cancer HPV prevalence surveys: a pooled analysis. Lancet. 2005;366:991-8.

11. Lai CH, Huang HJ, Hsueh S, Chao A, Lin CT, Huang SL, Chao FY, Qiu JT, Hong JH, Chou HH, Chang TC. Human papillomavirus genotype in cervical cancer: a population-based study. Int J Cancer. 2007;120(9):1999-2006.

12. Franceschi S, Rajkumar $\mathrm{T}$, Vaccarella $\mathrm{S}$, Gajalakshmi V, Sharmila A, Snijders PJ, et al. Human papillomavirus and risk factors for cervical cancer in Chennai, India: a case-control study. Int J Cancer. 2003;107(1):127-33.

Cite this article as: Maheshwari S, Nautiyal R, Kotwal A, Chandra S. Prevalence and distribution of various human papillomavirus genotypes in women with high risk for cervical carcinoma. Int J Reprod Contracept Obstet Gynecol 2020;9:2498-503. 